\title{
XANES and EXAFS Study of a Platinum Phthalocyanine
}

Young H. Chang, * Kyung H. Choi, a Warren T. Ford, $c$ Sung June Cho a,b and Ryong Ryoo*a,b

a Department of Chemistry and $\mathrm{b}$ Center for Molecular Science, Korea Advanced Institute of Science and Technology, Taeduk Science Town, Taejon, 305-701 Korea

c Department of Chemistry, Oklahoma State University, Stillwater, OK 74078, USA

Extended $X$-ray absorption fine structure (EXAFS) and $X$-ray absorption near-edge structure (XANES) studies on [octa(2-ethylhexyloxy)phthalocyaninato]platinum [PtL] as a film at room temperature suggest that the structure consists of non-planar, concave discotic molecules packed perpendicular to the stacking axis.

Phthalocyanines are synthetic analogues of porphyrins with a structure similar to that of haemoglobin and chlorophyll. ${ }^{1}$ The molecular stacking and electronic structure of metallophthalocyanines attract great attention because they exhibit many remarkable capabilities e.g. as catalysts or as one-dimensional or semi-conductors in electronic or opto-electronic devices. ${ }^{2}$ While the configuration of phthalocyanine molecules is well known, structural investigation of highly-branched metallophthalocyanines is difficult as structural disorder due to sidechains causes difficulties in obtaining good crystals of suitable size. ${ }^{3}$ In this paper, we show that extended X-ray absorption fine structure (EXAFS) and X-ray absorption near-edge structure (XANES) techniques are particularly suitable for the structural and electronic investigation of highly-branched liquid-crystalline metallophthalocyanines.

[Octa(2-ethylhexyloxy)phthalocyaninato]platinum [PtL] was prepared by heating $\mathrm{PtCl}_{2}$ and 1,2-dicyano-4,5-di(2-ethylhexyloxy)benzene in sealed Pyrex tubing at $583 \mathrm{~K}$ for $36 \mathrm{~h} .{ }^{4} \mathrm{~A}$ sample of [PtL] was deposited on Kapton film $(500 \mu \mathrm{m}$, Du Pont) by evaporation of a chloroform solution under vacuum at room temperature. The film thickness was chosen to give an $\mathrm{X}$-ray absorption $\Delta \mu_{\mathrm{X}} \approx 1$, at the $\mathrm{Pt} \mathrm{L}_{\mathrm{III}}$ edge. ${ }^{5} \mathrm{~A} \mathrm{Pt}$ foil and $\left[\mathrm{Pt}\left(\mathrm{NH}_{3}\right)_{4}\right]\left[\mathrm{NO}_{3}\right]_{2}$ (Aldrich, $>99 \%$ ) were used as standards. The X-ray absorption measurement was carried out at room temperature using Beam Line 10B at the Photon Factory of the National Laboratory for High Energy Physics (KEK-PF), Tsukuba. The injection beam energy was $2.5 \mathrm{GeV}$. The ring current was $272 \mathrm{~mA}$. The monochromator was a Si(311) channel cut with a typical resolution $\triangle E / E=1 \times 10^{-4}$ at the $\mathrm{Pt}$ $\mathrm{L}_{\text {III }}$ edge. The energy steps in the XANES and EXAFS regions were 0.5 and $1.5 \mathrm{eV}$, respectively. The $X$-ray absorption was measured using gas ionization chambers. The detector gases for $I$ (transmitted X-ray intensity) and $I_{\mathrm{o}}$ (incident X-ray intensity) were $100 \% \mathrm{Ar}$ and $75 \% \mathrm{~N}_{2}-25 \% \mathrm{Ar}$ mixture, respectively.

In Fig. 1, the XANES spectrum of [PtL] taken above the $\mathrm{L}_{\mathrm{II}}$ absorption edge is compared with that of $\left[\mathrm{Pt}\left(\mathrm{NH}_{3}\right)_{4}\right]\left[\mathrm{NO}_{3}\right]_{2}$. Both appear to have similar structures, in

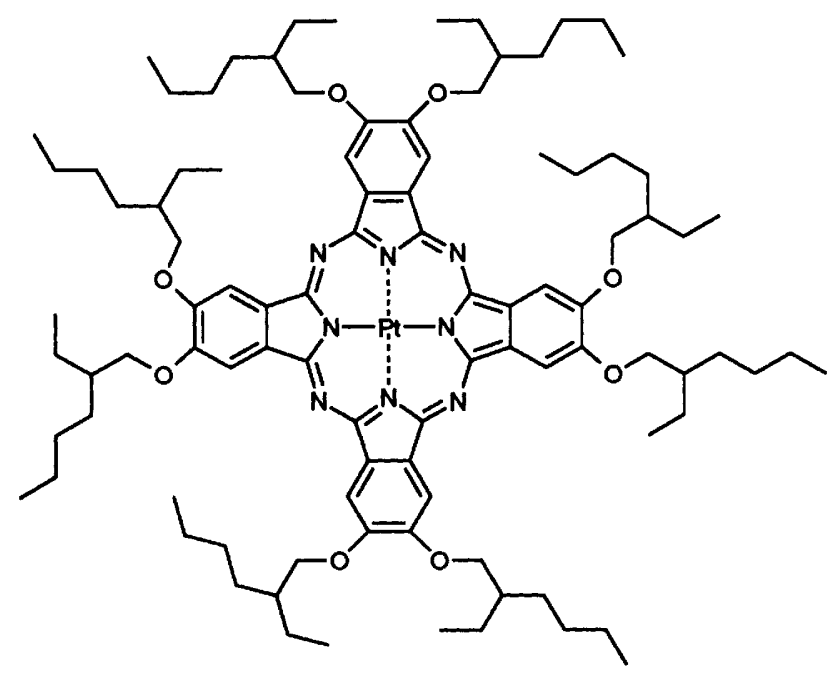

[PIL] which four $\mathrm{N}$ atoms are coordinated to $\mathrm{Pt}^{\mathrm{II}}$ with planar geometries. The difference of white line heights (Fig. 1) between the compounds is of interest. Moreover, the X-ray absorption spectra show energy shifts from $\mathrm{Pt}$ foil at the $\mathrm{Pt} \mathrm{L}_{\mathrm{III}}$ edges of 1.3 and $2.0 \mathrm{eV}$ respectively for $\left[\mathrm{Pt}\left(\mathrm{NH}_{3}\right)_{4}\right]\left[\mathrm{NO}_{3}\right]_{2}$ and $[\mathrm{PtL}]$. These successive energy shifts indicate a high oxidation state of $\mathrm{Pt}($ i.e. $>2)$ in [ $\mathrm{PtL}]$. A possible reason for the greater white line height of $[\mathrm{PtL}]$ compared to $\left[\mathrm{Pt}\left(\mathrm{NH}_{3}\right)_{4}\right]\left[\mathrm{NO}_{3}\right]_{2}$ may be due to electron delocalization into the phthalocyanine moiety. However, it should be noted that while correlations between white line heights and oxidation states exist in some cases, there are other examples where this is not observed. 6

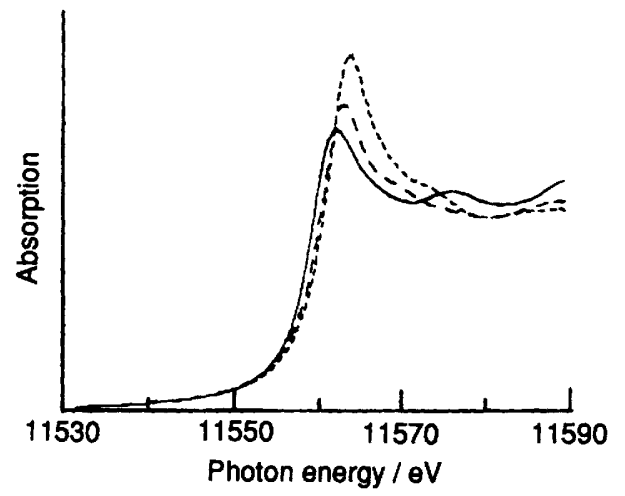

Fig. 1 Near-edge spectrum of $\mathrm{Pt}$ foil $(-),\left[\mathrm{Pt}\left(\mathrm{NH}_{3}\right)_{4}\right]\left[\mathrm{NO}_{3}\right]_{2}$ $(---)$ and $[\mathrm{PtL}](--)$ at the $\mathrm{Pt} \mathrm{L}_{\mathrm{III}}$ edge after normalization
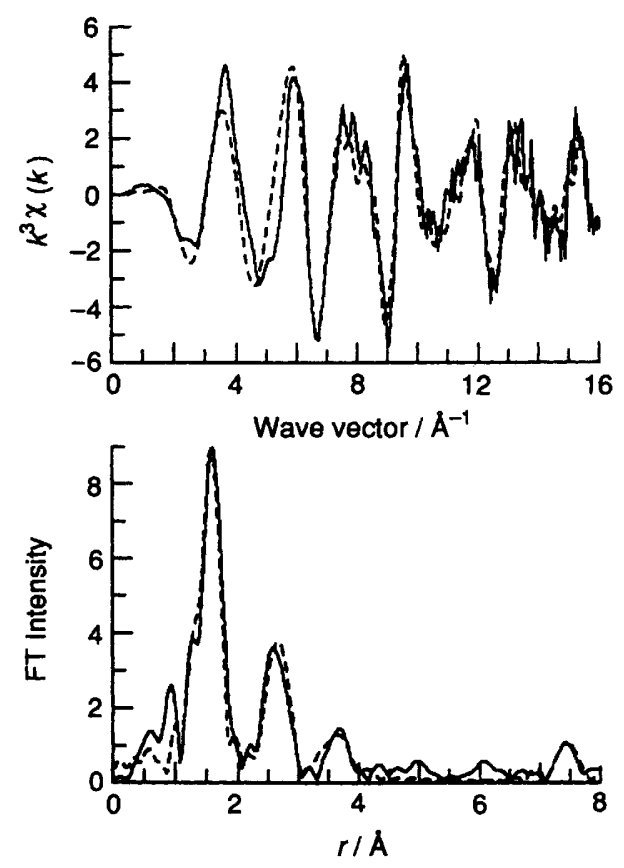

Fig. 2 The EXAFS spectrum $\left[k^{3} \chi(k)\right]$ and its Fourier transform for [PtL]; experimental (- ${ }^{-}$and theoretical fit using FEFF code $(\cdots)$ 
Further information on the electron density of the $d$ band will be gained by analysing difference spectra between the $\mathrm{L}_{\mathrm{III}}$ and $\mathrm{L}_{\mathrm{II}}$ edges. ${ }^{6}$ If the $\mathrm{Pt}$ atom in $[\mathrm{PtL}]$ assumes a higher oxidation state than +2 , it is likely that the molecule can adopt a non-planar configuration, or the $\mathrm{Pt} \cdots \mathrm{Pt}$ distance can be affected significantly. This may explain why Vacus et al. ${ }^{7}$ obtained an unusually short Pt $\cdots P$ Pt distance of $3.29 \AA$ in a hexagonal columnar phase of [octa(dodecyloxy)phthalocyaninato]platinum. The short $\mathrm{Pt}-\mathrm{Pt}$ distance was attributed to attractive overlap of $d_{z^{2}}$ Pt oribtals.

The EXAFS oscillation $\left[k^{3} \chi(k)\right]$ of $[\mathrm{PtL}]$ and its Fourier transform are shown in Fig. 2. There are four major peaks in the Fourier transform. Each of these was inverse Fourier transformed to obtain a Fourier-filtered $\chi(k)$ function in the range $1.7<k<16.0 \AA^{-1}$. A detailed curve-fitting analysis was performed for the $\chi(k)$ curve as follows. The $\chi(k)$ curve corresponding to the $1.10<r<2.06 \AA$ peak was fitted using, as reference, a $\chi(k)$ for $\mathrm{Pt}-\mathrm{N}$ which was obtained after the same Fourier filtering of an experimentally obtained EXAFS spectrum of $\left[\mathrm{Pt}\left(\mathrm{NH}_{3}\right)\right]\left[\mathrm{NO}_{3}\right]_{2}$. Curve fitting for the other peaks was carried out similarly with the references for $\mathrm{Pt} \cdots \mathrm{C}$ and $\mathrm{Pt} \cdots \mathrm{Pt}$ pairs which were theoretically generated using the FEFF-3 code taking into account the single-scattering, manybody and curved-wave effects. ${ }^{8}$ The amplitude reduction factor for $\mathrm{Pt}$ used in the $\chi(k)$ generation was $0.89 .{ }^{8}$ Theoretical references were used because suitable experimental references were not available. The bond distance and the coordination number were assumed again until, for example, the Fourier-filtered $\chi(k)$ curve in the region $7.05<r<7.70 \AA$ agreed with a new $\chi(k)$ for the second nearest Pt...Pt pair which was obtained by the FEFF- 5 code considering multiple scattering effects. ${ }^{9}$

The EXAFS curve fitting for the range $1.10<r<3.04 \AA$ was carried out in two ways: one with the assumption of a planar discotic [PtL] structure, and the other without such a restriction. The $R$-factors $\dagger$ representing the fitting errors in
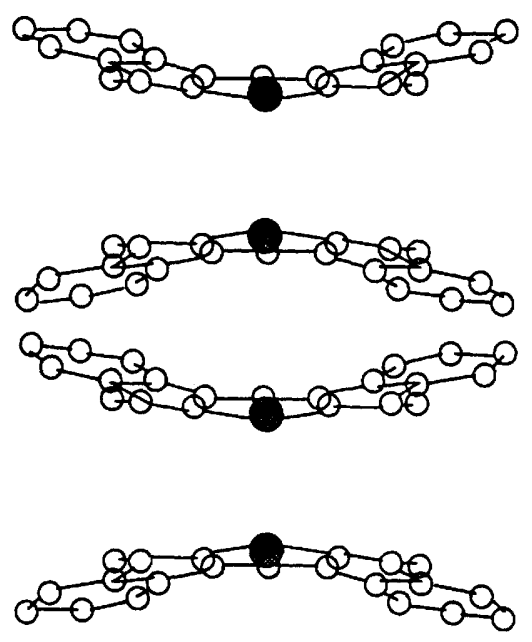

Fig. 3 Schematic view of the molecular stacking in [PtL] proposed from EXAFS spectroscopy

Table 1 The structural parameters from EXAFS curve fitting for [PtL]

\begin{tabular}{llll}
\hline Shell & $\mathrm{CN}^{a}$ & $r b / \AA$ & $\Delta \sigma^{2 c / \AA^{2}}$ \\
\hline Pt-N & 2 & $1.91(0.02)$ & 0.0042 \\
Pt-N & 2 & $1.98(0.02)$ & 0.0010 \\
Pt $\cdots \mathrm{C}$ & 4 & $2.98(0.03)$ & 0.0008 \\
Pt $\cdots \mathrm{C}$ & 4 & $3.35(0.03)$ & 0.0048 \\
Pt $\cdots \mathrm{Pt}$ & 1 & $3.69(0.05)$ & 0.0043 \\
Pt $\cdots \mathrm{Pt}$ & 1 & $4.04(0.05)$ & 0.0064 \\
$\mathrm{Pt} \cdots \mathrm{Pt}$ & 2 & $7.57(0.10)$ & 0.0058
\end{tabular}

$\bar{a} \mathrm{CN}=$ Coordination number. ${ }^{b}$ Bond distance. $c$ Debye-Waller factor $( \pm 0.0015)$. these cases were 0.434 and 0.306 , respectively. Thus, the curve fitting agreed much better for a concave discotic structure. The curve fitting for $\mathrm{Pt} \cdots \mathrm{Pt}$ peak in the region $1.10<r<4.20 \AA$ was carried out in two ways: one with a single nearest neighbour distance, and the other assuming two different $\mathrm{Pt} \cdots \mathrm{Pt}$ distances; the $R$-factors were 0.421 and 0.320 respectively, suggesting that the Pt...Pt nearest neighbour distances between the concave $[\mathrm{PtL}]$ disks were inequivalent. The best curve-fitting result that was obtained with such non-planar concave discotic [PtL] moieties and two different $\mathrm{Pt} \cdots \mathrm{Pt}$ neighbour distances gave a good fit both in the $k$ and $r$ spaces as shown in Fig. 2. The resulting optimised structure of [PtL], based on our best EXAFS curve fit, is shown in Fig. 3 and the structural parameters are listed in Table 1.

In Fig. 3 , the [PtL] molecules are packed perpendicularly to the stacking axis with the Pt atoms located along the stacking axis. The unusually strong intensity of the $7.5 \AA$ peak in the Fourier transform EXAFS spectrum supports such collinear stacking of $\mathrm{Pt}$ atoms. The $\mathrm{Pt}$ atom is located on the central axis $0.15 \AA$ above the mean plane of the four isoindole $\mathrm{N}$ atoms. The phthalocyanine moiety is distorted from planarity with the benzene ring directed away from the $\mathrm{Pt}$ atom, which is in good agreement with the high $\mathrm{Pt}$ oxidation state indicated from XANES spectroscopy. The distorted molecular structure shown in Fig. 3 contrasts with the planar structure obtained by Brown $^{10}$ from single-crystal $\mathrm{X}$-ray diffraction (XRD) of unsubstituted (phthalocyaninato)platinum. This difference may be attributed to flexibility of the highly-branched phthalocyanine moiety and the branched $[\mathrm{PtL}]$ seems difficult to crystallize due to large thermal disorder at room temperature. Although our curve fitting agreed better with two nearest $\mathrm{Pt}$...Pt interatomic distance (i.e., 3.69 and $4.04 \AA$ ) rather than a single distance $(3.87 \AA)$, this result does not necessarily mean that the Pt $\cdots$ Pt distances are fixed at these values at room temperature, but the $\mathrm{Pt} \cdots \mathrm{Pt}$ distance may oscillate through fluctuation of the $[\mathrm{PtL}]$ molecule in the solid state. However, it is still difficult to speculate as to why the optimised molecular structure differs from an oblique discotic planar structure which was recently proposed from powder XRD of the same molecule at room temperature. ${ }^{4}$ Our curve fitting clearly agreed better with the concave structure shown in Fig. 3 than a planar structure. If such non-planar [PtL] molecules are packed with non-uniform Pt...Pt distances, but tilted with respect to the columnar axis, the $\mathrm{Pt} \cdots \mathrm{Pt} \cdots \mathrm{Pt}$ orientation will deviate substantially from linearity. However, our EXAFS calculation (FEFF-5) showed that the $7.5 \AA$ peak in Fig. 2 should completely disappear if this angle shows a deviation of as little as $5^{\circ}$.

To summarize, our XANES study has indicated that the oxidation state of platinum in $[\mathrm{PtL}]$ is certainly higher than +2 . The EXAFS study has suggested a concave structure for the molecule and we may attribute the non-planar structure to attractive overlap $\mathrm{d}_{z^{2}} \mathrm{Pt}$ orbitals. We also speculate that molecules of $[\mathrm{PtL}]$ undergo thermal fluctuation at room temperature. Further work such as variable-temperature EXAFS measurements will be very useful to clarify the structural intricacies of [PtL].

We thank Korea Science and Engineering Foundation, the Photon Factory (Proposal No. 92G193), and Pohang Accelerator Laboratory for their support of this research.

Received, 29th September 1993; Com. 3/05872G

\footnotetext{
Footnote

$\dagger R=\sum_{i}^{N}\left(1 / \sigma_{i}\right)\left[\left|\chi^{\operatorname{exptl}}\left(k_{i}\right)-\chi^{\text {theor }}\left(k_{i}\right)\right|\right]$, where $\chi^{\text {expt1 }}\left(k_{i}\right)$ and $\chi^{\text {theor }}\left(k_{i}\right)$ are the experimental and theoretical EXAFS and $\sigma_{i}$ is defined by $\left.1 / \sigma_{i}=k_{i}{ }^{3} \sum_{j}^{N} k_{j}{ }^{3} \mid \chi_{j} \operatorname{expt1}^{2}\left(k_{j}\right)\right\}$.
} 


\section{References}

1 F. H. Moser and A. L. Thomas, The Phthalocyanines, CRC Press, Boca Raton, FL, 1983; Phthalocyanines, vols. 1-3, ed. C. C Leznoff and A. B. P. Lever, VCH, New York, 1989, 1993.

2 J. Simon, F. Tournilhaec and J.-J. André, Nouv. J. Chim., 1986. 10, 295; J. Simon, F. Tournilhaec and J.-J. André, New J. Chem., $1987,11,383$.

3 P. Weber, D. Guillon and A. Skoulios, Liq. Cryst., 1991, 9, 369.

4 W. T. Ford, L. Sumner, W. Zhu, Y. H. Chang, P. Urn, K. H. Choi, P. A. Heiney and N. C. Maliszewskyj, New J. Chem., in the press.

5 B. K. Teo, EXAFS: Basic Principles and Data Analysis, SpringerVerlag, New York, 1986; Principles, Application, Techniques of EXAFS, SEXAFS, and XANES, ed. D. C. Koningsberger and R. Prins, Wiley, New York, 1988.
6 J. A. Horsley, J. Chem. Phys., 1982, 76, 1451; B. Moraweck, A. J. Renouprez, E. K. Hill and R. Baudoing-Savois, J. Phys. Chem., 1993, 97, 4288; F. W. Lytle, P. S. P. Wei, R. B. Greegor, G. H. Via and J. H. Sinfelt, J. Chem. Phys., 1979, 70, 4849; A. N. Mansour, J. W. Cook Jr. and D. E. Sayers, J. Phys. Chem., 1984, 88, 2330 ,

7 J. Vacus, P. Doppelt, J. Simon and G. Memetzidis, J. Mater. Chem., 1992, 2, 1065.

8 J. J. Rehr, J. Mustre de Leon, S. I. Zabinsky and R. C. Albers, J. Am. Chem. Soc., 1991, 113, 5135; J. Mustre de Leon, J. J. Rehr, S. I. Zabinsky and R. C. Albers, Phys. Rev. B, 1991, 44, 4146.

9 J. J. Rehr, R. C. Albers and S. I. Zabinsky, Phys. Rev. Lett., 1992, 23, 3397.

10 C. J. Brown, J. Chem. Soc. A, 1968, 2494. 
